\title{
Access to Healthcare for Vulnerable Asians in the United States
}

\author{
By Deborah Kim-Lu*
}

\begin{abstract}
Though the Patient Protection and Affordable Care Act is a pivotal step toward universal coverage in the US and substantial progress has been made since its passing in 2010, significant risks and insurmountable barriers still exist for underserved communities. This study closely examined the barriers that the top four most uninsured subgroups face in accessing healthcare (Bangladeshi, Cambodian, Korean, and Pakistani communities). Combining quantitative and qualitative approaches, this study consisted of interviews with 24 national health experts and advocates on Asian health and a survey of a non-probability sample of 107 Koreans in the Tri-State region (Connecticut, New Jersey, and New York). Findings indicated that structural barriers, such as cost and employment/occupation types, have a significant impact on access to healthcare. Further high uninsurance rates (40\%) appear to be interrelated to the high occurrence of self-employment and employment in the ethnic economy (57\%).
\end{abstract}

Keywords: Access to healthcare, Healthcare equity, Immigrant health and healthcare disparities, Occupational constraints.

\section{Introduction}

Congressional Budget Office projections indicate that the Affordable Care Act legislation will decrease the number of uninsured (nonelderly) residents by 32 million, leaving approximately 23 million uninsured US residents in 2019, after the bill's provisions are fully implemented. An estimated one third of these 23 million uninsured Americans will include illegal immigrants. The rest will be composed of individuals who do not enroll in Medicaid, despite being eligible, and who choose to opt out or are exempted from paying the annual penalty (US Congressional Budget Office 2011). Without proper representation and better understanding of the structural and cultural barriers to healthcare for vulnerable groups, it is likely that political pressure and desire to improve and extend services will dissipate once the majority of the population is provided with basic medical services. Asians are particularly vulnerable. Contrary to common stereotypes such as the model minority myth, which perceives all Asians as highly financially successful, entrepreneurial, and well-educated, there is convincing evidence that immigrant populations like these have lower rates of Access to Healthcare (AHC) than US natives and are more likely to be in poverty, which poses a financial barrier to obtaining healthcare (Lebrun 2011, LeClere et al. 1994). Asians are relatively new immigrants to the US, who face numerous other insurmountable barriers because they possess high rates of limited English proficiency, low levels of civic participation and acculturation, and are greatly underrepresented in government in relation to other groups of color. A large percentage of the overall Asian population is foreign-born, close

${ }^{*}$ PhD Graduate, City University of New York Graduate Center, USA. 
to $67 \%$, (US Census Bureau 2010). In sum, these characteristics put them at a higher risk of remaining uninsured and underserved because cuts often occur at a point of least political resistance (Aday and Andersen 1974, Mechanic 1978).

The purpose of this study was to examine the barriers the most vulnerable Asian subgroups face in accessing the US healthcare delivery system. Using 2010 US census data, this study chose the top four most uninsured: the Bangladeshi, Cambodian, Korean, and Pakistani subgroups. According to the 2010 census figures, these four Asian subgroups possess the highest uninsurance rates among all Asian subgroups, ranging from $24.1 \%$ to $20.3 \%$, which are significantly higher than the national uninsured rate of $15.5 \%$ and the aggregate Asian American uninsured rate of $15.7 \%^{1}$. Of important mention is the fact that several studies at the regional and state levels that exist in the Health Services Research literature on the top four most uninsured Asian subgroups indicate that in actuality, uninsurance rates may be significantly higher than the US Census Bureau estimates (Brown et al. 2001, Kim 2004, Shin et al. 2005, The Commonwealth Fund 2001, Tirodkar et al. 2011). Several of these studies have consistently reported higher uninsurance rates for Koreans, including estimates from the Commonwealth Fund (2001) at 52\%, a rate far above the $24.1 \%$ figure provided by 2010 US census data estimates. Furthermore, according to TrinhShrevin et al. (2009), Koreans' uninsurance rates across data sets, age groups, and time rank the worst in coverage among all Asian subgroups and remain high regardless of market conditions or generosity of state public insurance programs.

In sum, these disparities in health insurance coverage suggest that a number of Asian subgroups, including the subgroups being examined in this study, do not fit the popular notion of a "model minority", a common stereotype in which all Asians are perceived as highly financially successful, entrepreneurial, and well-educated. Because disadvantaged and medically underserved populations are often the ones that encounter numerous barriers to preventive healthcare, such high rates of uninsurance that have not been evident in more advantaged Asian subgroups warrant further examination.

\section{Research Approach and Methods}

This study included two phases of data collection. The first phase included semi-structured qualitative interviews with national health experts and advocates from nonprofit organizations as well as various government agencies throughout the US. The second phase focused on the design and implementation of the Access to Healthcare Survey for Koreans in the US in the Tri-State region of the US (Connecticut - New Jersey - New York). To minimize bias in the survey sample, this study employed a quota sampling method, the nonprobability equivalent of stratified random samples. Other sampling criteria included ensuring that basic demographic variables such as gender and age were reasonably distributed.

\footnotetext{
${ }^{1}$ Case selection based on health insurance coverage rates reported in the 2010 US Census American Community Survey.
} 
The survey instrument was based on major themes derived in this study's review of the Health Services Research and Comparative Health Policy literature and themes derived from the interviews. The first part of the survey, Part I: Participant Information, measured variables such as (1) demographic characteristics such as age, gender, marital status, length of residence in the US, (2) acculturation, (3) socioeconomic indicators such as educational attainment, income, employment type, (4) health insurance coverage and regular source of care, (5) health status and healthcare utilization, (6) community healthcare services utilization, (7) political participation, (8) religiosity and other beliefs. The second part of the survey included a Likert scale, Part II: Access to Healthcare, which measured patterns of structural, system, and cultural barriers. An example item is: "It is easy to find affordable quality health care". The instrument was coded on a six-point Likert scale from "Strongly Disagree" to "Strongly Agree". The survey instrument underwent internal consistency estimates of reliability, which generated a value of 0.757 for the Chronbach's alpha coefficient and 0.784 for the split-half coefficient (unequal length). As they both exceeded 0.70 , each indicated satisfactory reliability (Tabachnick and Fidell 2007).

In total, 24 in-person interviews were self-administered and 107 surveys were collected. For the interviews, the study applied a coding process to the notes incurred from these interviews for the purposes of discerning themes, patterns; as well as any similarities and differences among these subgroups (Park 2011). Atlas.ti 7 was the software package used for data analysis. Survey data was inputted into SPSS for analyses. Descriptive statistics and correlations were conducted to determine the relationships between AHC and educational attainment, income, acculturation, and religiosity. Analysis of variance was used to determine differences in healthcare access among groups across: (1) personal and household income levels, (2) employment status and employment work types, (3) acculturation levels, and (4) religiosity levels. Chi-square analyses were used to examine differences in healthcare access and income levels and educational attainment by place of education.

\section{Findings}

\section{Interview Results}

In terms of structural barriers and system barriers in accessing healthcare, the most common barriers cited by interviewees included: (1) occupational constraints due to high rates of self-employment or work in the informal ethnic labor market that are not conducive to accessing healthcare (e.g., difficulty accessing healthcare due to long working hours or because of the loss of wages), (2) high costs of health insurance, (3) limited hours, (4) lack of transportation, (5) lack of familiarity with patient and immigration rights, (6) lack of knowledge and resources to navigate a complex healthcare system, and (7) lack of awareness of available public health services provided by the government and community-based organizations as well as public program eligibility rules. The most common cultural barriers cited by interviewees included: (1) limited 
English proficiency, (2) unique family structure dynamics (e.g., reliance on family members to coordinate healthcare and collective decision-making), (3) lack of cultural competency among providers, (4) reliance on alternative medicine, (5) physical practices connected to religious beliefs such as fasting as well as fatalistic views of illness, and (6) distrust of the American healthcare system.

\section{Occupational Constraints}

Almost all interviewees (90\%) noted occupational constraints as being one of the major root causes for the poor AHC - most immigrants work in the informal ethnic labor markets making it very difficult to take time off from work or pay for healthcare. Some of these subgroups (i.e. Koreans and Pakistanis) possess high concentrations of high self-employment rates and often lack of employer-based insurance. Hence, the majority of these subgroups receive healthcare in a piecemeal and fragmented fashion.

\section{Information and Resources}

A number of interviewees $(60 \%)$ also mentioned that these communities' awareness of available public health insurance programs and community-based healthcare and social services is generally lacking. They explained that while the mission of many community-based organizations is to provide social services, including education about the US healthcare system, community-based organizations have very little reach because of inadequate funding and resources in relation to their target populations. Some interviewees $(40 \%)$ mentioned that nonprofit organizations that serve people of color compete with each other fiercely for funding and are, therefore, underfunded. Asians are the most negatively impacted: one interviewee noted that while they comprise $13 \%$ of the population in New York City, only $1 \%$ of the total New York City community healthcare budget is allocated to Asian community-based programs as a whole and the rest allocated to other groups of color. Some interviewees attributed the lack of community-based funding to an absence of strong leadership and lack of political representation of Asians in the New York City region.

\section{Patient and Immigration Rights}

Most interviewees (70\%) mentioned that because of limited English proficiency and high levels of isolation, these communities also lack knowledge of patient and immigration rights, which greatly impacts the manner in which they seek care. In some instances, individuals are unclear of their rights and do not access the healthcare system because they think treatments must be paid in advance or because they fear that if they are unable to pay, the debt will ultimately be carried over to their children. Relatedly, many in these communities do not know they have a right to a translator when seeking care in hospitals and other major healthcare institutions. There is also widespread confusion about public assistance programs and their impact on 
immigration status, even among the legally documented. Individuals do not want to jeopardize their immigration status and forego seeking public resources to avoid at all costs being classified as a public charge.

\section{Alternative Medicine, Medical Tourism, and Religion}

Most interviewees $(70 \%)$ noted that healthcare tends to become the last priority behind earning a living to cover housing and other basic needs, taking care of family members (including extended family members), and providing educational opportunities for their children. Because of these competing demands of daily life, these Asian subgroups are at greater risk of developing a habit of seeking alternative methods of treatment because they are cheaper and quicker alternatives to obtaining Western treatment. One interviewee explained that often times, individuals are not aware that treating health issues with alternative medicine can be quite problematic. In actuality, treating chronic diseases with alternative medicine is frequently incompatible and bigger health issues and risks arise because individuals are not likely to disclose usage of alternative medicines if they seek care from a physician. Also, many may seek Western medicine methods of treatment at later stages of disease when it is too late to treat.

Interviewees commented on the popularity of medical tourism, especially among those with dual citizenship who return to their home country for lowcost healthcare services and medication. However, follow-up care becomes a problem when the primary care physician is in another country. Lastly, some interviewees $(40 \%)$ indicated that religion may negatively impact healthcare access. For instance, individuals attempt to cure their physical ailments through prayer and believe that only God has the power to heal their ailments. Another interviewee explained that in some instances, individuals go long periods without eating as part of their fasting tradition, a practice that is not compatible with treating chronic diseases such as diabetes and other ailments. Even when they are being treated by Western physicians, individuals may not always disclose their practices and their physicians may be unaware of these dangers.

\section{Results of the Access to Healthcare Survey for Koreans in the US}

Of the 107 respondents ( $35 \%$ response rate), 54\% were males between the ages of 18 and older, over $60 \%$ were college graduates, with most of them completing their education in South Korea (53\%). More than half $(63 \%)$ have resided in the US for more than 20 years. A little over half of the sample speak English well or very well (57\%) while a little under half do not speak English well or not at all (44\%). Of those surveyed, $44 \%$ reported an income of $\$ 20,000$ to $\$ 60,000$. In terms of household income, $26 \%$ of households reported making $\$ 40,000$ or less. Approximately $90 \%$ of the sample reported being employed with $57 \%$ reported being self-employed and $40 \%$ report having no insurance. Among those who have insurance coverage, the majority (26\%) have insurance through their employers, while a small number of them (8\%) are either insured through their spouses and 5\% purchase insurance on their own. Informants with 
Medicare (7\%) and Medicaid (19\%) coverage are mostly elders, who meet the requirements for dual-eligibility. $48 \%$ reported using traditional Korean medicine, with $37 \%$ utilizing treatment 1 or more times in the last 12 months. Lastly, a small portion $(11 \%)$ reported travelling to South Korea within the last 5 years to obtain healthcare.

AHC was measured by patterns of structural, system, and cultural barriers. The scale assessed a total of 21 healthcare access barriers, including cost, limited office hours, distrust in the US healthcare system, etc. The Likert scale ranged from "Strongly Disagree" (1), "Disagree" (2), "Slightly Disagree" (3), "Slightly Agree" (4), "Agree" (5), and "Strongly Agree" (6). Table 1 provides a summary of the mean and standard deviation for all barrier questions. In this context, the higher the mean, the stronger the presence of the barrier. Strong presence of barriers were detected for cost and system barriers, including trouble with paying for insurance $(\mu=3.75)$ and the American healthcare system is confusing $(\mu=3.95)$. In addition, cultural barriers such as reliance on family to coordinate healthcare $(\mu=4.35)$ and feeling more comfortable with Korean doctors $(\mu=3.99)$ were strong barriers. Furthermore, a strong preference for Western medicine was found $(\mu=4.83)$.

Table 1. Summary of Barriers for AHC for Koreans in the US

\begin{tabular}{|l|c|c|c|c|}
\hline Barrier Question & $\begin{array}{c}\text { Barrier } \\
\text { Type }\end{array}$ & $\mathbf{N}$ & $\begin{array}{c}\mathbf{M} \\
(\boldsymbol{\mu})\end{array}$ & $\begin{array}{c}\text { SD } \\
(\boldsymbol{\sigma})\end{array}$ \\
\hline I rarely skip medication due to cost (Reversed) & Cost & 102 & 2.98 & 1.72 \\
\hline I have an easy time communicating with doctors (Reversed) & System & 103 & 2.47 & 1.28 \\
\hline I have trouble paying for my health insurance & Cost & 102 & 3.75 & 1.74 \\
\hline I have no problems paying for my medical bills (Reversed) & Cost & 97 & 3.54 & 1.53 \\
\hline Finding transportation is difficult & System & 100 & 3.26 & 1.59 \\
\hline I often put off getting medical care due to cost & Cost & 99 & 2.99 & 2.07 \\
\hline I rarely have to wait a long time to see a doctor (Reversed) & System & 98 & 2.61 & 1.37 \\
\hline It is easy to find affordable quality healthcare (Reversed) & Cost & 99 & 3.90 & 1.71 \\
\hline HC facilities in my area have limited hours & System & 101 & 2.48 & 1.55 \\
\hline HC facilities in my area offer limited services & System & 100 & 3.49 & 1.81 \\
\hline The American HC System is confusing & System & 99 & 3.95 & 1.51 \\
\hline Enrolling in public health insurance is difficult & System & 98 & 3.51 & 1.57 \\
\hline I rely on my family to coordinate my HC & Cultural & 101 & 4.35 & 1.63 \\
\hline My religious views do not prevent/delay care (Reversed) & Cultural & 99 & 4.35 & 1.53 \\
\hline Public insurance impacts immigration status & System & 97 & 3.15 & 1.65 \\
\hline I know I can request an interpreter at a hospital (Reversed) & System & 98 & 2.13 & 1.28 \\
\hline I prefer conventional Western medicine (Reversed) & Cultural & 99 & 4.83 & 1.08 \\
\hline Korean media is my main source of information & Cultural & 98 & 3.68 & 1.63 \\
\hline I feel more comfortable with Korean doctors & Cultural & 98 & 3.99 & 1.65 \\
\hline Receiving public assistance is disgraceful & Cultural & 98 & 2.62 & 1.49 \\
\hline I do not trust the American HC system & Cultural & 97 & 3.18 & 1.55 \\
\hline Source: Auth's estimations & & &
\end{tabular}

Source: Author's estimations.

\section{Relationship between AHC and Educational Attainment}

Educational attainment level of respondents is fairly high. Over $60 \%$ of this sample have bachelor's degrees and above (master's, professional, or doctorate degrees). Over half completed their education in their country of origin, South 
Korea (53\%). Relationships between AHC and educational attainment revealed that increases in educational attainment were slightly associated with less AHC. Results of the Pearson correlation indicated that there was a significant negative correlation between educational attainment and AHC, $r=-0.244, n=97, p=0.02$. Of notable importance is the significant association found between educational attainment and place where the respondent received their education (South Korea versus US). Results of the chi-square test of independence indicated that there was a significant association between educational attainment and place of education, $\chi^{2}(7, n=104)=37.96, p<0.001$. In other words, those respondents that were educated in the US had greater AHC than those that were educated in South Korea.

\section{Relationship between Access to Healthcare and Income}

Respondents' individual incomes vary significantly, ranging between no income and over $\$ 200,000$. Of those surveyed, $17 \%$ reported an annual income of $\$ 20,000$ or less, $44 \%$ reported an income of $\$ 20,000$ to $\$ 60,000,24 \%$ reported an annual income of $\$ 80,000$ to $\$ 120,000$, another $2 \%$ reported an income of $\$ 120,001$ to $\$ 140,000$, and $4 \%$ reported an income of over $\$ 200,000$. In terms of household income, $12 \%$ of households in this sample reported an annual income of $\$ 20,000$ or less, $26 \%$ reported an income of $\$ 20,000$ to $\$ 60,000,29 \%$ reported an annual income of $\$ 60,000$ to $\$ 100,000,20 \%$ reported an income of $\$ 100,001$ to $\$ 140,000,5 \%$ reported an income of $\$ 140,001$ to $\$ 200,000$, and $8 \%$ reported an income of over $\$ 200,000.26 \%$ of households reported making $\$ 40,000$ or less.

Table 2. Chi-square Test of Goodness of Fit Observed and Expected Frequencies: Individual Income

\begin{tabular}{|c|c|c|c|}
\hline & Observed N & Expected N & Residual \\
\hline $\mathbf{\$ 5 , 0 0 0 - 1 0 , 0 0 0}$ & 7 & 10.4 & -3.4 \\
\hline $\mathbf{\$ 1 0 , 0 0 1 - 1 5 , 0 0 0}$ & 4 & 10.4 & -6.4 \\
\hline $\mathbf{\$ 1 5 , 0 0 1 - 2 0 , 0 0 0}$ & 6 & 10.4 & -4.4 \\
\hline $\mathbf{\$ 2 0 , 0 0 1 - 4 0 , 0 0 0}$ & 25 & 10.4 & 14.6 \\
\hline $\mathbf{\$ 4 0 , 0 0 1 - 6 0 , 0 0 0}$ & 20 & 10.4 & 9.6 \\
\hline $\mathbf{\$ 6 0 , 0 0 1 - 8 0 , 0 0 0}$ & 12 & 10.4 & 1.6 \\
\hline $\mathbf{\$ 8 0 , 0 0 1 - 1 0 0 , 0 0 0}$ & 14 & 10.4 & 3.6 \\
\hline $\mathbf{\$ 1 0 0 , 0 0 1 - 1 2 0 , 0 0 0}$ & 10 & 10.4 & -.4 \\
\hline $\mathbf{\$ 1 2 0 , 0 0 1 - 1 4 0 , 0 0 0}$ & 2 & 10.4 & -8.4 \\
\hline Over $\mathbf{\$ 2 0 0 , 0 0 0}$ & 4 & 10.4 & -6.4 \\
\hline
\end{tabular}

Source: Author's estimations.

Results of the bivariate correlation revealed that there was no significant linear relationship between individual income and AHC mean scores, $\mathrm{r}=-0.188$, $\mathrm{n}=94, \mathrm{p}=0.07$. On the other hand, the results of the correlation between total household income and AHC mean scores, $r=-0.343, n=93, p=0.001$ indicated that decreases in total household income were related to decreases in AHC. A chi-square test of goodness of fit indicated that for personal income, the $\$ 20,001$ to $\$ 40,000$ group was more likely to be insured with an observed frequency of 
25 versus an expected frequency of $10.4, \chi^{2}(9, \mathrm{n}=104)=48.5, \mathrm{p}<0.001$ (Table 2). For household income, the $\$ 80,001$ to $\$ 100,000$ income group was most likely to be insured, having an observed frequency of 23 versus an expected frequency of $7.8, \chi^{2}(12, \mathrm{n}=101)=68.3, \mathrm{p}<0.001($ Table 3$)$.

Table 3. Chi-square Test of Goodness of Fit Observed and Expected Frequencies: Household Income

\begin{tabular}{|c|c|c|c|}
\hline & Observed N & Expected N & Residual \\
\hline $\mathbf{\$ 5 , 0 0 0 - 1 0 , 0 0 0}$ & 5 & 7.8 & -2.8 \\
\hline $\mathbf{\$ 1 0 , 0 0 1 - 1 5 , 0 0 0}$ & 3 & 7.8 & -4.8 \\
\hline $\mathbf{\$ 1 5 , 0 0 1 - 2 0 , 0 0 0}$ & 4 & 7.8 & -3.8 \\
\hline $\mathbf{\$ 2 0 , 0 0 1 - 4 0 , 0 0 0}$ & 15 & 7.8 & 7.2 \\
\hline $\mathbf{\$ 4 0 , 0 0 1 - 6 0 , 0 0 0}$ & 11 & 7.8 & 3.2 \\
\hline $\mathbf{\$ 6 0 , 0 0 1 - 8 0 , 0 0 0}$ & 6 & 7.8 & -1.8 \\
\hline $\mathbf{\$ 8 0 , 0 0 1 - 1 0 0 , 0 0 0}$ & 23 & 7.8 & 15.2 \\
\hline $\mathbf{\$ 1 0 0 , 0 0 1 - 1 2 0 , 0 0 0}$ & 16 & 7.8 & 8.2 \\
\hline $\mathbf{\$ 1 2 0 , 0 0 1 - 1 4 0 , 0 0 0}$ & 4 & 7.8 & -3.8 \\
\hline $\mathbf{\$ 1 4 0 , 0 0 1 - 1 6 0 , 0 0 0}$ & 4 & 7.8 & -3.8 \\
\hline $\mathbf{\$ 1 6 0 , 0 0 1 - 1 8 0 , 0 0 0}$ & 1 & 7.8 & -6.8 \\
\hline $\mathbf{\$ 1 8 0 , 0 0 1 - 2 0 0 , 0 0 0}$ & 1 & 7.8 & -6.8 \\
\hline Over $\mathbf{\$ 2 0 0 , 0 0 0}$ & 8 & 7.8 & 0.2 \\
\hline
\end{tabular}

Source: Author's estimations.

\section{Relationship between AHC and Employment Types}

Approximately $90 \%$ of the sample reported being employed with $57 \%$ reporting as self-employed. In terms of employment hours, $83 \%$ of the sample work full-time and 9\% work part-time. More specifically, $15 \%$ hold positions in private-for-profit companies, $4 \%$ in private-not-for-profit organizations, $6 \%$ in government organizations, $19 \%$ in small business, and $49 \%$ report being selfemployed. For those who indicated their current occupational type (63\%), 10\% report having a management, business, and financial occupation; $25 \%$ report having a professional occupation; $34 \%$ report having a service occupation; and $22 \%$ report having occupations in sales, office and administrative support, and construction and extraction. Furthermore, when queried about previous employment outside the US, the figure for service occupations held before emigration to the US (13\%) is much lower than the figure (34\%) for service occupations held after emigration.

Results of the analysis of variances comparing the employment status groups on healthcare status means scores indicated that there was no significant difference in means scores, $\mathrm{F}(2,92)=1.29, \mathrm{p}=0.28$ (Tables 4 and 5). Results of analysis of variance examining mean healthcare access differences among the groups in the employment work type variable indicated there were no significant mean differences between any of the employment work type groups, $\mathrm{F}(4$, 83) $=1.30, \mathrm{p}=0.278$ (Tables 6 and 7). 
Table 4. Descriptive Statistics ANOVA: Employment Status

\begin{tabular}{|l|c|c|c|c|c|}
\hline \multirow{2}{*}{ Employed } & \multirow{2}{*}{$\mathbf{N}$} & $\mathbf{M}$ & \multirow{2}{*}{ SD } & \multicolumn{2}{|c|}{ 95\% CI } \\
\cline { 5 - 6 } & & & & Lower & Upper \\
\hline Self-employed & 31 & 3.24 & 0.67 & 2.99 & 3.48 \\
\hline Unemployed & 55 & 3.44 & 0.58 & 3.28 & 3.60 \\
\hline Total & 9 & 3.55 & 0.88 & 4.23 & 2.48 \\
\hline
\end{tabular}

Source: Author's estimations.

Table 5. ANOVA Table: Employment Status

\begin{tabular}{|l|c|c|c|c|c|}
\hline & $\boldsymbol{S S}$ & $\boldsymbol{D} \boldsymbol{f}$ & $\boldsymbol{M S}$ & $\boldsymbol{F}$ & $\boldsymbol{p}$ \\
\hline Between Groups & 1.07 & 2 & 0.54 & 1.29 & 0.28 \\
\hline Within Groups & 38.11 & 92 & 0.41 & & \\
\hline Total & 39.18 & 94 & & & \\
\hline
\end{tabular}

Source: Author's estimations.

Table 6. Descriptive Statistics ANOVA: Employment Work Type

\begin{tabular}{|l|c|c|c|c|c|}
\hline & $\mathbf{N}$ & $\mathbf{M}$ & $\mathbf{S D}$ & \multicolumn{2}{|c|}{$\mathbf{9 5 \%}$ CI } \\
\cline { 5 - 7 } & & & & Lower & Upper \\
\hline Private for-profit company & 15 & 3.28 & 0.752 & 2.87 & 3.70 \\
\hline Private not-for-profit organization & 4 & 2.89 & 0.838 & 1.56 & 4.22 \\
\hline Government organization & 6 & 3.10 & 0.465 & 2.61 & 3.58 \\
\hline Small business & 17 & 3.37 & 0.720 & 3.00 & 3.74 \\
\hline Self-employed & 46 & 3.49 & 0.591 & 3.32 & 3.67 \\
\hline
\end{tabular}

Source: Author's estimations.

Table 7. ANOVA Table: Employment Work Type

\begin{tabular}{|l|c|c|c|c|c|}
\hline & $\boldsymbol{S S}$ & $\boldsymbol{D} \boldsymbol{f}$ & $\boldsymbol{M S}$ & $\boldsymbol{F}$ & $\boldsymbol{p}$ \\
\hline Between Groups & 2.19 & 5 & 0.548 & 1.30 & 0.278 \\
\hline Within Groups & 35.11 & 83 & 0.423 & & \\
\hline Total & 37.30 & 88 & & & \\
\hline
\end{tabular}

Source: Author's estimations.

\section{Relationship between AHC and Acculturation}

The concept of acculturation was measured through simplified indicators that are frequently used in the Health Services Research literature, including dichotomous measures of length of stay and language proficiency. Among the respondents, length of residence in the US ranges from less than five years to more than 40 years. More than half $(63 \%)$ have resided in the US for more than 20 years. A little over half of the sample speak English well or very well (57\%) while a little under half do not speak English well or not at all (44\%).

Higher acculturation levels were measured using two different variables, length of stay in the US and English proficiency. Results of the correlation between healthcare access and length of stay in the US indicated that there was no significant linear relationship between the two variables, $r=-0.196, n=97$, $\mathrm{p}=0.054$. However, there was a strong positive linear relationship between English proficiency and healthcare access, $\mathrm{r}=0.544, \mathrm{n}=96, \mathrm{p}<0.001$, where greater English proficiency was associated with greater AHC. Given the 
significant correlation between English proficiency and the limited range of English proficiency scores (only 4 categories), an analysis of variance was conducted to determine if there were significant differences in healthcare acesss among the four English proficiency groups. Results of the analysis of variance indicate that there were significant differences among the groups, $\mathrm{F}(3,92)=14.95$, $\mathrm{p}<0.001$ (Tables 8 and 9). To determine which groups were significantly different from one another, post hoc tests were conducted using the Bonferroni adjustment. Results of the post hoc test indicated that those who spoke English not well $(\mathrm{M}=3.81, \mathrm{SD}=0.570)$ had significantly less $\mathrm{AHC}$ than both those who spoke well $(\mathrm{M}=3.26, \mathrm{SD}=0.550)$ and those who spoke English very well $(\mathrm{M}=2.88$, $\mathrm{SD}=0.514)$. Those who did not speak English at all $(\mathrm{M}=3.60, \mathrm{SD}=0.067)$ had significantly different AHC than those who spoke very well, well, or not well.

Table 8. Descriptive Statistics ANOVA: English Proficiency

\begin{tabular}{|l|c|c|c|c|c|}
\hline & $\boldsymbol{N}$ & $\boldsymbol{M}$ & $\boldsymbol{S D}$ & \multicolumn{2}{|c|}{ 95\% CI } \\
\cline { 5 - 6 } & & & & Lower & Upper \\
\hline Very well & 23 & 2.88 & 0.514 & 2.65 & 3.10 \\
\hline Well & 34 & 3.26 & 0.550 & 3.07 & 3.45 \\
\hline Not well & 36 & 3.81 & 0.570 & 3.62 & 4.01 \\
\hline Not at all & 3 & 3.60 & 0.086 & 3.38 & 3.81 \\
\hline
\end{tabular}

Source: Author's estimations.

Table 9. ANOVA Table: English Proficiency

\begin{tabular}{|l|c|c|c|c|c|}
\hline & $\boldsymbol{S S}$ & $\boldsymbol{d} \boldsymbol{f}$ & $\boldsymbol{M S}$ & $\boldsymbol{F}$ & $\boldsymbol{P}$ \\
\hline Between Groups & 13.25 & 3 & 4.42 & 14.95 & 0.000 \\
\hline Within Groups & 27.19 & 92 & 0.30 & & \\
\hline Total & 40.44 & 95 & & & \\
\hline
\end{tabular}

Source: Author's estimations.

\section{Relationship between AHC and Religiosity}

Most of the respondents attend a religious organization on a regular basis, approximately $61 \%$ attend either daily or on a weekly basis. When respondents were asked about their religious beliefs in this study, a good portion of the sample indicated that illness is or may be a punishment from God (18\%) and illness can or may only be healed by God (17\%). When asked whether illness results in reputational problems for the individual or family, only $9 \%$ of the sample responded "Yes" and 13\% responded "Maybe".

Religiosity was measured using three different variables: religious attendance, illness results from sin, and sickness can be healed only by God. Results of the correlation analysis indicated that there was no significant linear relationship beween AHC and religious attendance, $r=0.041, n=97, p=0.687$. Results of the ANOVA using the Browne-Forsythe robust test of equality of means indicated that there were no significant differences among the three groups for the illness results from sin variable, $\mathrm{F}(2,9.24)=1.474, \mathrm{p}=0.278$ (Tables 10 and 11). The ANOVA analysis for the sickness can be healed only by God variable also yielded no significant differences among the yes, no, and maybe groups, $F(2,93)=1.12$, $\mathrm{p}=0.331$ (Tables 12 and 13). 
Table 10. Descriptive Statistics ANOVA: Illness Results from Sin

\begin{tabular}{|l|c|c|c|c|c|}
\hline \multirow{2}{*}{} & \multirow{2}{*}{$\boldsymbol{N}$} & $\boldsymbol{M}$ & \multirow{2}{*}{$\boldsymbol{D D}$} & \multicolumn{2}{|c|}{ 95\% CI } \\
\cline { 5 - 6 } & & & & Lower & Upper \\
\hline No & 78 & 3.38 & 0.59 & 3.25 & 3.52 \\
\hline Yes & 6 & 3.88 & 1.09 & 2.73 & 5.03 \\
\hline Maybe & 12 & 3.12 & 0.66 & 2.70 & 3.53 \\
\hline
\end{tabular}

Source: Author's estimations.

Table 11. ANOVA Table: Illness Results from Sin

\begin{tabular}{|l|c|c|c|c|}
\hline & F & df1 & df2 & P \\
\hline Brown-Forsythe & 1.47 & 2 & 9.24 & 0.278 \\
\hline
\end{tabular}

Source: Author's estimations.

Table 12. Descriptive Statistics ANOVA: Sickness can be Healed Only by God

\begin{tabular}{|l|c|c|c|c|c|}
\hline \multirow{2}{*}{} & \multirow{N}{*}{$\boldsymbol{N}$} & $\boldsymbol{M}$ & \multirow{2}{*}{$\boldsymbol{S D}$} & \multicolumn{2}{|c|}{ 95\% CI } \\
\cline { 5 - 6 } & & & & Lower & Upper \\
\hline No & 78 & 3.34 & 0.63 & 3.20 & 3.48 \\
\hline Yes & 7 & 3.72 & 0.85 & 2.93 & 4.50 \\
\hline Maybe & 11 & 3.44 & 0.69 & 2.98 & 3.90 \\
\hline
\end{tabular}

Source: Author's estimations.

Table 13. ANOVA Table: Sickness can be Healed Only by God

\begin{tabular}{|l|c|c|c|c|c|}
\hline & SS & Df & MS & F & P \\
\hline Between Groups & 0.95 & 2 & 0.47 & 1.12 & 0.33 \\
\hline Within Groups & 39.31 & 93 & 0.42 & & \\
\hline
\end{tabular}

Source: Author's estimations.

\section{Discussion}

The impact of cultural factors, such as the profound preference for traditional medicine, distrust of US healthcare system, religious beliefs, and medical tourism practices to some extent have been overly emphasized. Rather, this study shows that structural barriers such as the high occurrence of selfemployment (57\%) and work in the ethnic economy have a significant impact on AHC. While the link between high self-employment rates and high uninsurance rates has been well documented, this study deviates from the literature in that it shows these rates are disproportionally higher among Asians. In terms of selfemployment rates among Koreans, Min (2006) reported lower rates of selfemployment rates at 39\% in the New York area and Min and Kim-Lu (2014) reported rates at $20.6 \%$ based on US Census 2007-2011 national dataset. In addition, the high uninsurance rate found in this study's Korean sample (40\%) is significantly higher than national data figures reported by the 2010 US census data estimates $(24 \%)$.

Exploring trends for educational attainment, income, occupation and industry types for the Korean sample support the argument that high rates of self-employment $(57 \%)$ do not necessarily indicate a cultural propensity for entrepreneurship but rather a strategy used to overcome disadvantages they face 
in the US labor market. Although Koreans possess high levels of educational attainment, many Korean immigrants adopt a pragmatic strategy of "accommodation without assimilation" because they are likely to have earned their degrees in South Korea and lack knowledge of English, which forces them to seek self-employment opportunities or work in the ethnic economy (Park 2012). Facing disadvantages in the US labor market, they default to more service-oriented jobs, either by setting up low-startup-cost small businesses or working as low-wage workers in the ethnic labor market.

Moreover, contrary to mainstream beliefs, this study underscores the notion that self-employment does not necessarily generate financial success - for instance, a substantial portion of this study's Korean sample reported working in service occupations (34\%), with total households earning $\$ 40,000$ or less $(26 \%)$. Their poor socioeconomic status is associated with health and healthcare disparities, including lack of health insurance coverage, which is the main mechanism in which individuals in the US obtain care. While Koreans in this sample showed a significant preference for western medicine, they are likely to utilize traditional medicine since these services are more convenient and affordable.

\section{Conclusions}

This study suggests that the way in which vulnerable Asian populations behave is highly dependent on how the US healthcare delivery system is designed, organized, and implemented. Because health insurance is closely tied to the labor market structure of the US, employment and occupation types seem to be the most significant among the structural barriers Asians face in accessing healthcare. These institutional barriers have the most significant impact in preventing Asians from accessing healthcare and living healthy lives. Despite the expected impact of the Affordable Care Act in reducing uninsured rates, future efforts to remedy structural barriers will require a multifaceted approach that moves towards integrating vulnerable populations, such as immigrants, into the mainstream healthcare system and establishes targeted interventions such as comprehensive case management services. Nonetheless, in order to enact real change within the healthcare system for vulnerable populations like these, we must begin by embedding the central idea of equity very deeply in US culture - that everyone should have access to, and be able to use, appropriate, good quality, and affordable healthcare.

\section{References}

Aday LA, Andersen R (1974) A framework for the study of access to medical care. Health Services Research Fall: 208-220.

Brown ER, Ponce, N, Rice T (2001) The state of health insurance in California: Recent trends, future projects. Los Angeles, California: UCLA Center for Health Policy Research. 
Kim YO (2004) Access to hepatitis B vaccination among Korean American children in immigrant families. Journal of Health Care Poor Underserved 15(2): 170-182.

Lebrun LA (2011) Access to primary and preventative health care among foreignborn adults in Canada and the United States. Johns Hopkins University.

LeClere FB, Jensen L, Biddlecom AE (1994) Healthcare utilization, family context, and adaptation among immigrants to the United States. Journal of Health Sociology Behavior 35: 370-384.

Mechanic D (1978) Illness behavior, In Medical Sociology. A comprehensive text (2nd edn.). New York: The Free Press (pp. 249-289).

Min PG (2006) Asian Americans: Contemporary trends and issues. California: Sage, Thousand Oaks.

Min PG, Kim-Lu D (2014) "Korean Americans" Intergenerational Transition in Their Occupational Adaptation: From Small Businesses to the Mainstream Economy Book Chapter, In PG Min, S Noh, Second-Generation Korean Experiences in the US and Canada. London: Lexington Books (pp. 35-52).

Park JW (2012) Demographic profile of Koreans in Canada, In S Noh, A Kim, M Noh Korean immigrants in Canada: Perspectives on migration, integration and the family. Toronto, Canada: University of Toronto Press.

Park L (2011) Entitled to nothing: The struggle for immigrant health care in the age of welfare reform. New York, NY: New York University Press.

Shin H, Song H, Kim J, Probst JC (2005) Insurance, acculturation, and health service utilization among Korean-Americans. Journal of Immigrant Health 7(2): 65-74.

Tabachnick BG, Fidell LS (2007) Experimental designs using ANOVA. Thomson/Brooks/Cole.

The Commonwealth Fund (2001) 2001 Health care quality survey. Retrieved from http://goo.gl/XKiMOY. [Accessed: 21 February 2011]

Tirodkar M, Baker D, Makoul G, Khurana N, Paracha M, Kandula N (2011) Explanatory models of health and disease among South Asian immigrants in Chicago. Journal of Immigrant and Minority Health 13(2): 385-394.

Trinh-Shevrin C, Islam N, Rey M (2009) Asian American communities and health: Context, research, policy and action. San Francisco, California: Wiley.

US Census Bureau (2007-2011) American Community Survey 2007-2011-American Community Survey 5-Year Estimates. Generated by Deborah Kim-Lu using FactFinder. Retrieved from: http://goo.gl/vdhm3n. [Accessed: 1 March 2012]

US Census Bureau (2010) American Community Survey 2010-American Community Survey 1-Year Estimates. Generated by Deborah Kim-Lu using American FactFinder. Retrieved from: http://goo.gl/vdhm3n. [Accessed: 1 March 2012]

US Congressional Budget Office (2011) CBO's analysis of the major healthcare legislation enacted in March 2010. Retrieved from http://goo.gl/k1CEX2. [Accessed: 10 February 2012] 
